\title{
Nanostructure of Polystyrene- $b$-poly(2-Hydroxyethyl Methacrylate) and Derivatives with Phosphonic Diacid Groups
}

\author{
Vanessa Schmidt, ${ }^{*, a}$ Redouane Borsali ${ }^{b}$ and Cristiano Giacomelli ${ }^{a}$ \\ ${ }^{a}$ Departamento de Química, Universidade Federal de Santa Maria, \\ 97105-900 Santa Maria-RS, Brazil \\ ${ }^{b}$ Centre de Recherches sur les Macromolécules Végétales (CERMAV), BP53, \\ 38041 Grenoble Cedex 9, France
}

\begin{abstract}
A engenharia de superfícies para o posicionamento de biomoléculas é uma etapa fundamental para a produção de biochips. Neste estudo, descreve-se uma nova estratégia para a preparação de nanodomínios contendo grupos ácido fosfônicos, os quais se ligam a uma família de proteínas (anexinas), de forma reversível em função da presença de íons cálcio. A abordagem desenvolvida consistiu no uso de precursores de poliestireno- $b$-poli(metacrilato de 2-hidroxietila) (PS- $b$-PHEMA) sintetizados por polimerização radicalar por transferência de átomos (ATRP) para a obtenção de cilindros de PS $\left(f_{\mathrm{PS}}=0.25-0.27\right)$ dispostos em morfologia hexagonal numa matriz de PHEMA. Os grupos hidroxila pendentes do PHEMA foram, em seguida, parcialmente (20\%) convertidos em grupos ácido fosfônicos por reações sequenciais de fosforilação, sililação e metanólise. Este processo produziu derivados PS- $b$-P(HEMA-co-PEMA) que retêm a morfologia hexagonal, embora o grau de organização estrutural seja menor em relação aos precursores.
\end{abstract}

Surface engineering for precise positioning of biomolecules is of particular interest for controlled fabrication of biochips. In this study, a novel approach for the preparation of nanodomains with phosphonic diacid groups that were previously shown to reversibly bind to a family of proteins (annexins) in a calcium-dependent manner is described. The strategy makes use of polystyrene$b$-poly(2-hydroxyethyl methacrylate) (PS- $b$-PHEMA) precursors prepared by atom transfer radical polymerization (ATRP) to obtain hexagonally packed PS cylinders $\left(f_{\mathrm{PS}}=0.25-0.27\right)$ in a PHEMA matrix. The pendant hydroxyl groups of PHEMA are then partially ( $c a$. 20\%) converted into phosphonic diacid groups via sequential reactions involving phosphorylation, silylation and methanolysis. This process produces PS- $b$-P(HEMA-co-PEMA) derivatives that still retain the hexagonal morphology, but their degree of structural organization is reduced comparatively to the precursors.

Keywords: block copolymers, self-assembly, nanostructures

\section{Introduction}

Block copolymers have been used to fabricate nanomaterials via a bottom-up process in which a finite number of elementary building-blocks self-assemble hierarchically. ${ }^{1-7}$ It is now possible to design next-generation copolymer-based nanostructured thin films that simultaneously feature longrange order, stimulus-responsiveness, and spontaneously form versatile supramolecular structures. ${ }^{2,5-7}$

The development of functional films that are capable of interacting selectively with other systems, however,

*e-mail: vschmidt@ufsm.br still poses challenges to those working in this field as the incorporation of reactive chemical groups can exert a subtle influence over the balance of driving forces during the segregation process. ${ }^{8}$

From the perspective of functional (bio)nanomaterial engineering, polystyrene- $b$-poly(2-hydroxyethyl methacrylate) (PS- $b$-PHEMA) and polystyrene- $b$-poly(2hydroxyethyl methacrylate-co-2-phosphatethyl methacrylate) (PS- $b$-P(HEMA-co-PEMA)) block copolymers are of broad potential interest. Whilst the former has been reported to exhibit excellent blood compatibility and unique interactions with cells primarily due to segregation and exposition of PHEMA to living tissues, ${ }^{9,10}$ its derivative containing 
phosphonic diacid groups reversibly binds to Annexin-A5 proteins in a calcium-dependent manner. ${ }^{11,12}$ This certainly opens interesting avenues to the production of biochips ${ }^{13,14}$ from nano-organized thin films to which such proteins can be selectively distributed within the phosphorouscontaining microdomains. We hypothesized that this system would exhibit a more complex behavior compared to classical systems because of the additional functionality of the P(HEMA-co-PEMA) block. Besides the hydrogenbonding capability that is characteristic of PHEMA, ${ }^{15}$ this statistical segment also features ionizable units by virtue of a neutralization reaction involving phosphonic diacid moieties of PHEMA.

The self-organization of PS/PHEMA block copolymers has been previously investigated to a limited extent as compared to more classical systems. ${ }^{16,17}$ Senshu et al. ${ }^{16}$ successfully prepared nanostructured thin films of PHEMA- $b$-PS- $b$-PHEMA triblock copolymers, which upon casting from tetrahydrofuran (THF) and $N, N$-dimethylformamide (DMF) assembled to produce lamellae and hexagonal morphologies of PS cylinders dispersed in a PHEMA matrix, in spite of the fact that only the former phase is anticipated on the basis of the volume fraction of PS and theoretical phase diagrams. These authors also showed that the surface of as-cast films can be reversibly reconstructed by exposing samples to dry/wet conditions using water as solvent and thermal annealing. The change from predominantly hydrophobic (PS) to hydrophilic (PHEMA) surfaces is, however, accompanied by morphology transitions.

In this study, we focus on the preparation of well-defined nanodomains from PS- $b$-PHEMA diblock copolymers and its derivative PS- $b$-P(HEMA-co-PEMA) containing phosphonic diacid groups. Samples were obtained by solvent casting, and the effects of solvent nature, annealing and phosphorylation of PHEMA segment on the microphase separation processes are discussed.

\section{Experimental}

\section{Materials}

$\mathrm{PS}_{\mathrm{x}}$-block-PHEMA $\mathrm{y}_{\mathrm{y}}$ and $\mathrm{PS}_{\mathrm{x}}$-block-P(HEMA co-PEMA $A_{z}$ ) diblock copolymers (Figure 1) were synthesized via atom transfer radical polymerization (ATRP) followed by a three-step post-polymerization modification (phosphorylation, silylation and methanolysis) as previously described by Schmidt et al. ${ }^{11}$ Here and throughout the text, all copolymers will be referred to as $\mathrm{S}_{\mathrm{x}}-\mathrm{H}_{\mathrm{y}}$ or $\mathrm{S}_{\mathrm{x}}-\mathrm{H}_{\mathrm{y}} \mathrm{P}_{\mathrm{z}}$, where subscripts refer to the mean degrees of polymerization of each block. Briefly, polystyrene (PS) macroinitiators were firstly synthesized in bulk at $100{ }^{\circ} \mathrm{C}$ initiated by $\alpha$-bromoisobutyryl bromide in presence of $\mathrm{Cu} / \mathrm{PMDETA}$ catalyst. ${ }^{18}$ Gel permeation chromatography (GPC) results obtained using DMF eluent and PS standards indicated narrow molecular weight distributions $\left(M_{\mathrm{w}} / M_{\mathrm{n}} \leq 1.06\right)$, as listed in Table 1 . The bromo-terminated PS samples were subsequently used to initiate the ATRP of HEMA in MEK (methyl ethyl ketone)/1-propanol 70/30 (v/v) at $50{ }^{\circ} \mathrm{C}$ using $\mathrm{Cu} / \mathrm{bpy}$ catalyst. Under these experimental conditions, well-defined diblock copolymers were produced (Table 1). The degree of polymerization of PHEMA was determined by NMR (nuclear magnetic resonance) from the relative integrals of PHEMA and PS macronititator of known molecular weight (Table 1). In the next step, phosphorylation of PS- $b$-PHEMA was achieved using diethyl chlorophosphate in presence of triethylamine $\left(\mathrm{Et}_{3} \mathrm{~N}\right)$ in THF. The degree of substitution of - $\mathrm{OH}$ groups by $-\mathrm{P}(\mathrm{O})$ $\left(\mathrm{CH}_{3} \mathrm{CH}_{2}\right)_{2}$ in the resulting $\mathrm{PS}_{\mathrm{x}}$-block-P(HEMA -co-PEMA $)$ polymer was determined by ${ }^{1} \mathrm{H}$ NMR measurements. Molar mass analysis by GPC before and after the phosphorylating reaction demonstrated an increase in the molecular weight due to the incorporation of $-\mathrm{P}(\mathrm{O})\left(\mathrm{CH}_{3} \mathrm{CH}_{2}\right)_{2}$ in the polymer chain (Figure 2). Ionisable phosphonic diacid groups $\left(-\mathrm{P}(\mathrm{O})(\mathrm{OH})_{2}\right)$ were obtained after silylation using trimethylsilyl bromide followed by methanolysis. The macromolecular characteristics of samples investigated in this study are summarized in Table 1.
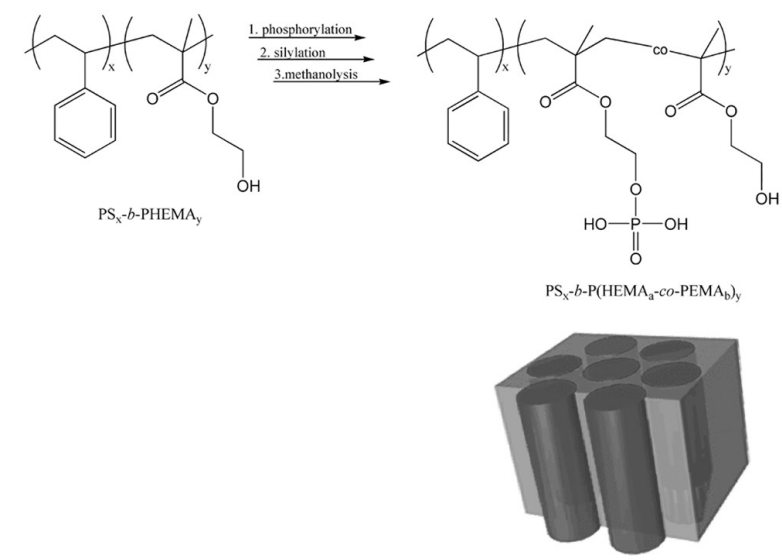

Hexagonally packed PS cylinders

Figure 1. Schematic representation of polystyrene- $b$-poly(2-hydroxyethyl methacrylate) (PS- $b$-PHEMA) and polystyrene- $b$-poly(2-hydroxyethyl methacrylate-co-2-phosphatethyl methacrylate) (PS- $b$-P(PEMA-coHEMA)) block copolymers, and the corresponding thin films with cylindrical microdomains of PS embedded in a matrix formed by PHEMA or P(HEMA-co-PEMA).

Preparation of self-assembled diblock copolymer samples

Samples of nano-organized diblock copolymers were cast from $10 \%(\mathrm{~m} / \mathrm{v})$ solutions using acetone or THF as 
Table 1. Macromolecular characteristics of PS- $b$-PHEMA (S-H) and PS- $b$-P(HEMA-co-PEMA) (S-HP) diblock copolymers

\begin{tabular}{|c|c|c|c|c|c|c|}
\hline Copolymer & $\mathrm{M}_{\mathrm{n}}(\mathrm{NMR})^{\mathrm{a}} /\left(\mathrm{g} \mathrm{mol}^{-1}\right)$ & $\mathrm{M}_{\mathrm{n}}(\mathrm{GPC})^{\mathrm{b}} /\left(\mathrm{g} \mathrm{mol}^{-1}\right)$ & $\phi_{\mathrm{PS}}{ }^{\mathrm{c}}$ & $\phi_{\text {PHEMA }}{ }^{\mathrm{c}}$ & $\phi_{\text {PEMA }}{ }^{c}$ & $M_{\mathrm{w}} / M_{\mathrm{n}}^{\mathrm{b}}$ \\
\hline S30 (macroinitiator) & & 3000 & - & - & - & 1.05 \\
\hline $\mathrm{S} 30-\mathrm{H} 70$ & 12200 & 34800 & 0.27 & 0.73 & - & 1.15 \\
\hline S30-H55P15 & - & - & 0.24 & 0.50 & 0.26 & 1.15 \\
\hline S55 (macroinitiator) & & 5700 & - & - & - & 1.06 \\
\hline S55-H145 & 24600 & 50000 & 0.25 & 0.75 & - & 1.14 \\
\hline S55-H120P25 & - & - & 0.22 & 0.56 & 0.22 & 1.14 \\
\hline
\end{tabular}

a Determined by ${ }^{1} \mathrm{H}$ NMR measurements in DMSO- $d_{6}$ using the ratio between methacrylic (PHEMA) and polymer backbone (PS + PHEMA) protons;

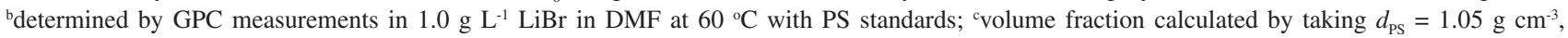
$d_{\text {PHEMA }}=1.15 \mathrm{~g} \mathrm{~cm}^{-3}$ and $d_{\text {PEMA }} c a .1 .0 \mathrm{~g} \mathrm{~cm}^{-3}$.

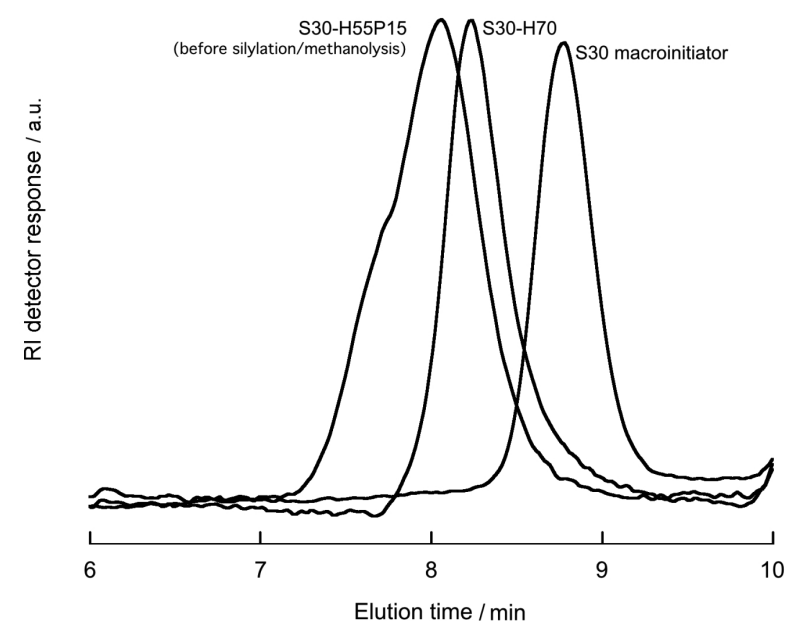

Figure 2. GPC traces of the S30 macroinitiator, S30-H70 diblock copolymer and S30-H55P15 modified sample before silylation and methanolysis (i.e. $22 \%$ of $-\mathrm{OH}$ groups converted into $\left.\mathrm{P}(\mathrm{O})\left(\mathrm{OCH}_{2} \mathrm{CH}_{3}\right)_{2}\right)$.

solvent. Solutions were initially stirred for $24 \mathrm{~h}$ followed by slow solvent evaporation at ambient temperature. After complete removal of the solvent, selected samples were annealed under vacuum for $24 \mathrm{~h}$ at temperatures ranging from 25 to $120^{\circ} \mathrm{C}$.

\section{Small- and wide-angle X-ray scattering (SAXS/WAXS)}

Small-angle X-ray scattering (SAXS) measurements were performed at the high brilliance beam line BM02 of the European Synchrotron Radiation Facility (ESRF, Grenoble, France) ${ }^{19}$ and also at the D11A-SAXS beamline of the Brazilian Synchrotron Light Laboratory (LNLS, Campinas-SP, Brazil). At the BM02 beamline, copolymer samples were placed in cylindrical capillaries of $1.5 \mathrm{~mm}$ internal diameter, the measurements were carried out at an incident energy of $16 \mathrm{keV}$ and scattered intensities were recorded at distance of $1.60 \mathrm{~m}$ using a two-dimensional charge coupled device detector (CCD, Ropper Scientific) with an active area of $44 \mathrm{~cm}^{2}$. The beam size was $0.3 \mathrm{~mm} \times 0.3 \mathrm{~mm}$. At the $\mathrm{D} 11 \mathrm{~A}$ beamline, measurements were carried out at $8.6 \mathrm{keV}$, and scattered intensities were recorded using a two-dimensional MarCCD detector (Rayonix) with an active area of $16 \mathrm{~cm}^{2}$ at distance of $1.60 \mathrm{~m}$. Depending on the beamline, the azimuthal integration was done using the FIT2D software developed by Hammersley ${ }^{20}$ or with the Bm2img software developed on BM02 beamline. ${ }^{21}$ The 2D images were corrected for dark current, distortions of the detector and normalized to the transmission and beam intensity.

\section{Results and Discussion}

\section{General features and behavior of polymers}

The molecular characteristics S-H and S-HP block copolymer systems used in this study are presented in Table 1 . The relative volume fractions $(f)$ of PS domains were estimated to be 0.27 and 0.25 for $\mathrm{S} 30-\mathrm{H} 70$ and S55-H145, respectively. These macromolecules had precise composition, architecture and narrow molecular weight distribution, which are important aspects for the production of well-defined nano-organized structures.

Derivatives featuring phosphonic diacid groups randomly distributed along the methacrylate block were obtained in a three-step phosphorylation/silylation/ methanolysis procedure. The polydispersity index after phosphorylation $\left(M_{\mathrm{w}} / M_{\mathrm{n}} \leq 1.37\right)$, at which step chains are still widely soluble in most organic solvents and suitable for GPC analysis, was clearly higher than for precursor samples $\left(M_{\mathrm{w}} / M_{\mathrm{n}} \leq 1.15\right)$. GPC traces provided in Figure 2 for a selected set of samples indicate a broader molar mass distribution after insertion of phosphate moieties, which is expected from the distinct contribution of the molar masses to $M_{\mathrm{w}}$ and $M_{\mathrm{n}}$ values for a constant number of chains. That is, the molar mass increase following the post-polymerization grafting of $-\mathrm{P}(\mathrm{O})\left(\mathrm{CH}_{3} \mathrm{CH}_{2}\right)_{2}$ groups to the polymer chain has stronger influence on $M_{\mathrm{w}}$ than $M_{\mathrm{n}}$, and 
hence the dispersity should increase. The same effect might also arise from dispersion in the phosphorylation degree. These changes in the chemistry and distribution of chains affected the self-assembly process (see below). The relative volume fraction of HEMA was always higher than PEMA, but the latter still imparted different solubility properties to P(HEMA-co-PEMA) segments, which could then be solubilized in both aqueous and organic (acetone and THF) media.

Self-assembled structures were prepared by solvent casting followed by thermal annealing. The annealing process removes the residual solvent and minimizes possible surface-induced non-equilibrium effects, thus increasing the probability of reaching morphologies in thermodynamic equilibrium. Synchrotron SAXS experiments were performed in order to examine the ordered phases originating from the self-assembly of S-H and S-HP copolymers at a large scale $\left(c a .10^{4} \mu \mathrm{m}^{2}\right)$. This approach is therefore suited for samples with possible heterogeneous organizations (structural defects).

SAXS profiles recorded at room temperature for S30-H70 and S55-H145 samples cast from an acetone solution and annealed at $120{ }^{\circ} \mathrm{C}$ are shown in Figure 3 . The scattering pattern reveals an organized morphology. The first order peak is located at $q^{*}=0.042 \AA^{-1}$ for S30-H70 and at $q^{*}=0.028 \AA^{-1}$ for S55-H145. In both cases, order peaks were observed at relative positions of $\sqrt{3} q^{*}, \sqrt{7} q^{*}, \sqrt{9} q^{*}, \sqrt{12} q^{*}$ and $\sqrt{17} q^{*}$. Such a sequence of scattering peaks is ascribed to cylindrical domains arranged in a hexagonal compact phase, ${ }^{22}$ which should be stable and in thermodynamic equilibrium at room temperature since the volume fraction of PS is $0.25-0.27$. The absence of the third order reflection at $\sqrt{4} q^{*}$ may be due to minima in the respective form factor. ${ }^{22}$ Indeed, this peak has been reported missing in several block copolymer systems. ${ }^{23}$

The diameter and separation between PS cylinders depended on the macromolecular characteristics of the building blocks (Table 2). Nanostructures made from S30-H70 consisted of $94 \AA$ PS cylinders with center-to-center (inter-columnar) distance $(d)$ of $173 \AA$. Therefore, the PS microdomains are $79 \AA$ apart at the shortest border-to-border distance, and this region is filled with PHEMA blocks. Considering a typical C-C bond length of $1.54 \AA$, a fully stretched S30-H70 chain is approximately $308 \AA$ long (PS length $=92 \AA$ and PHEMA length = $216 \AA$; bond angles not taken into account). Comparatively, the dimensions of nanodomains originated from self-organization of S55-H145 samples (longer chains) were a little larger than the previous case, as expected. PS cylinders measuring $136 \AA$ in diameter were separated $123 \AA$ from each other at the shortest distance
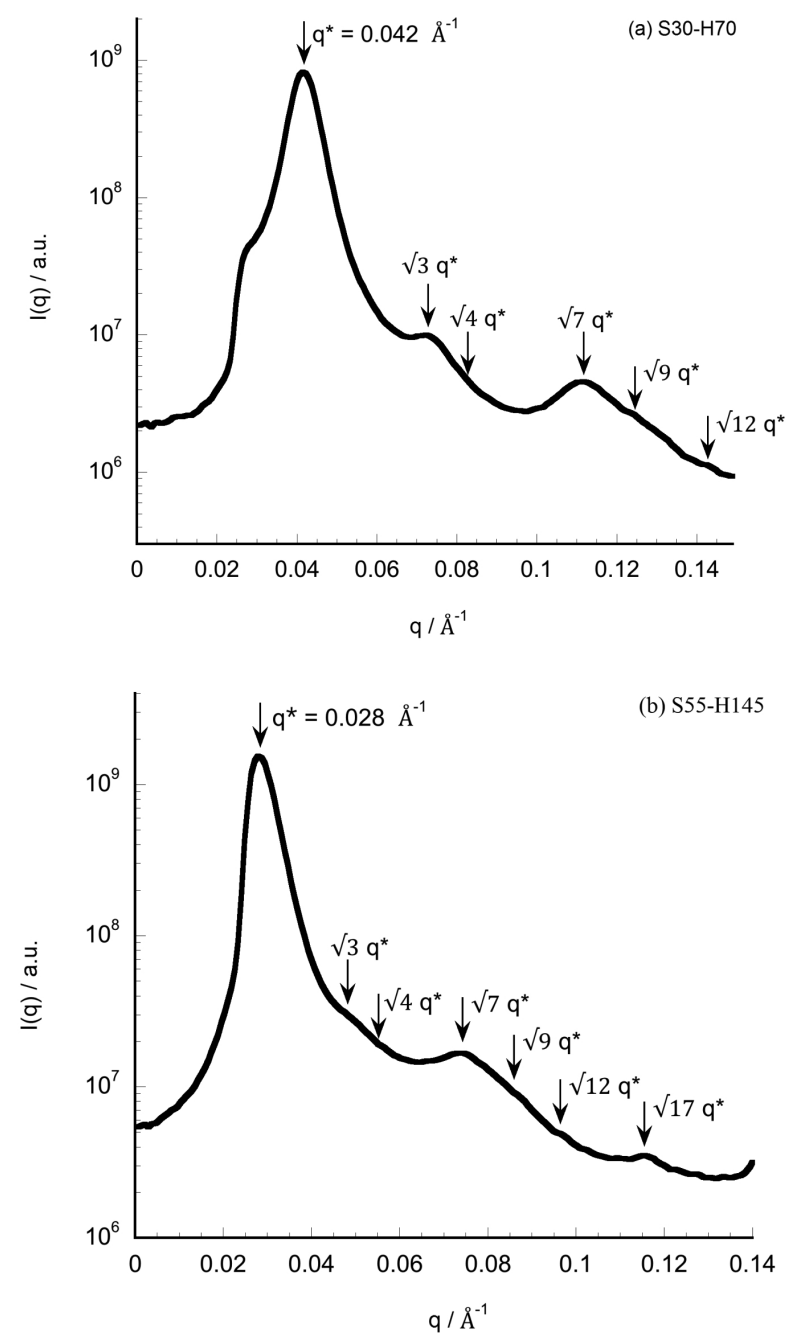

Figure 3. SAXS intensity profiles of $\mathrm{S} 30-\mathrm{H} 70$ (a) and $\mathrm{S} 55-\mathrm{H} 145$ (b) samples cast from $10 \% \mathrm{~m} / \mathrm{v}$ acetone solutions and annealed at $120^{\circ} \mathrm{C}$ for $24 \mathrm{~h}$. These SAXS patterns reveal that domains are organized.

Table 2. Morphological characteristics for nanostructures originated from self-assembly of S-H and S-HP derivatives

\begin{tabular}{lccccc}
\hline Copolymer & $d^{\mathrm{a}} / \AA$ & $d(\mathrm{PS})^{\mathrm{b}} / \AA$ & $d{\text { (shortest })^{\mathrm{c}} / \AA}^{\mathrm{a}}$ & $l$ (PS-stretched) $/ \AA$ & $l($ PHEMA-stretched $) / \AA$ \\
\hline S30-H70 & 173 & 94 & 79 & 92 & 216 \\
S30-H55P15 & 137 & 70 & 67 & 92 & 216 \\
S55-H145 & 259 & 136 & 123 & 169 & 447 \\
S55-H120P25 & 177 & 87 & 90 & 169 & 447
\end{tabular}

anter-columnar distance, $d=4 \pi /\left(q^{*} \sqrt{ } 3\right)$; ${ }^{b}$ diameter of PS cylinders, $d(\mathrm{PS})=2 \mathrm{R}(\mathrm{PS})=2 d\left(\sqrt{ } 3 \phi_{\mathrm{PS}} / 2 \pi\right)^{0.5}$; ${ }^{\text {s }}$ hortest border-to-border distance. 
by the PHEMA phase, and the inter-columnar distance was $259 \AA$. A fully stretched S55-H145 chain is around $616 \AA$ long (PS length $=169 \AA$ and PHEMA length $=447 \AA$ ). In both cases, the dimensions of microphases are smaller than molecular ones, hence implying that polymer chains assume an entangled conformation.

Figure 4 describes the variation of the scattered intensity using SAXS as a function of the azimuthal angle $2 \theta$ for the first-order peak at $q=0.028 \AA^{-1}$ of S55-H145 at room temperature. In addition, the inset of Figure 4 illustrates the scattering intensities focusing on this first-order peak. The observed profiles clearly reveal cylindrically ordered and oriented structure that is highlighted by the "powder pattern" that can be observed even for the second peak. The average distance between the peak maxima observed in Figure 4 is $60^{\circ}$, which is the classical value for a hexagonal oriented morphology, especially in high segregation strength.

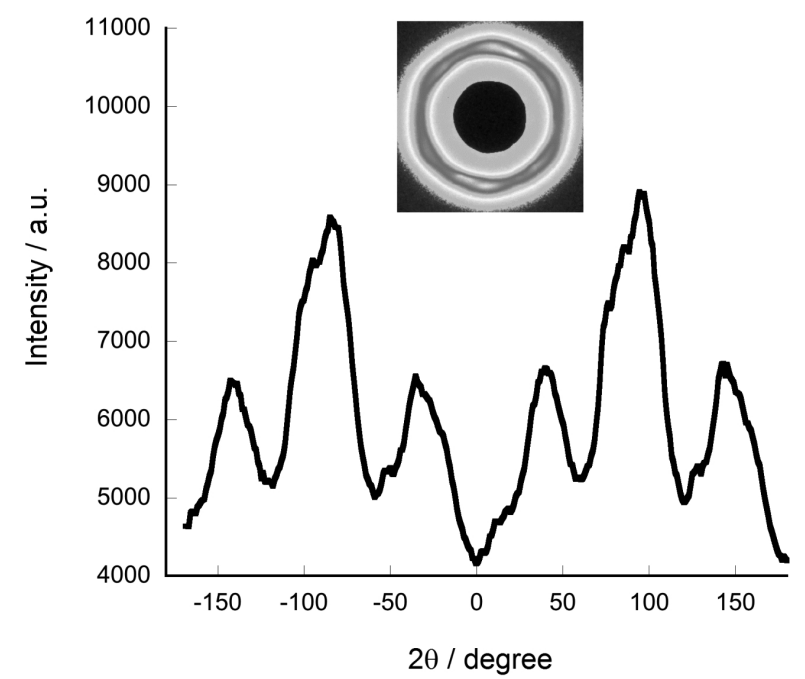

Figure 4. SAXS intensity distribution of the first-order peak as a function of the azimuthal angle $2 \theta$ for S55-H145 (the PS cylindrical domains are oriented parallel to the beam whose size was $0.3 \mathrm{~mm} \times 0.3 \mathrm{~mm}$ ).

\section{Effect of partial phosphorylation of PHEMA block}

The chemical structure of PHEMA segments, that constitute the matrix within which PS cylinders are hexagonally arranged, was found to dictate the microphase separation process. Copolymer casting produced scattering patterns with low resolution. This is attributed to a comparatively less structured self-organization within these materials after phosphorylation of pendant hydroxyl groups of PHEMA to afford a modified block consisting of randomly distributed HEMA and PEMA segments (P(HEMA-co-PEMA)). Such a behavior is probably prompted by the increase in the molecular weight distribution (see for instance Figure 2) and by the distinct nature of interactions between hydroxylated and phosphorylated motifs.

SAXS profiles recorded at room temperature for S30-H55P15 and S55-H120P25 samples (cast from an acetone solution and annealed at $120{ }^{\circ} \mathrm{C}$ ) having phosphorylation degrees of 0.24 and 0.22 , respectively, are shown in Figure 5. The curves feature a main scattering peak $\left(q^{*}\right)$ at low $q$-values. Two shoulders can also be identified in both cases at relative positions of $\sqrt{3} q^{*}$ and $\sqrt{7} q^{*}$. With the exception of the main peak, these were already the most intense signals for pristine (non-modified) samples, and in particular for $\mathrm{S} 30-\mathrm{H} 70$ (Figure 3a). Therefore, the presence of such scattering peaks confirms that the hexagonal structure is retained for PS- $b$-(P(HEMA-co-PEMA)). On the other hand, the characteristic morphological dimensions were considerably smaller after chemical modification (Table 2). For example, the inter-columnar spacing decreased from $173 \AA$ for S30-H70 (before phosphorylation) to $137 \AA$ for S30-H55P15 (after phosphorylation). This behavior is due to a different conformation of the matrix chains arising from stronger intermolecular interactions between phosphonic diacid and hydroxyl groups of P(HEMA-co-PEMA) as compared to the pristine PHEMA.

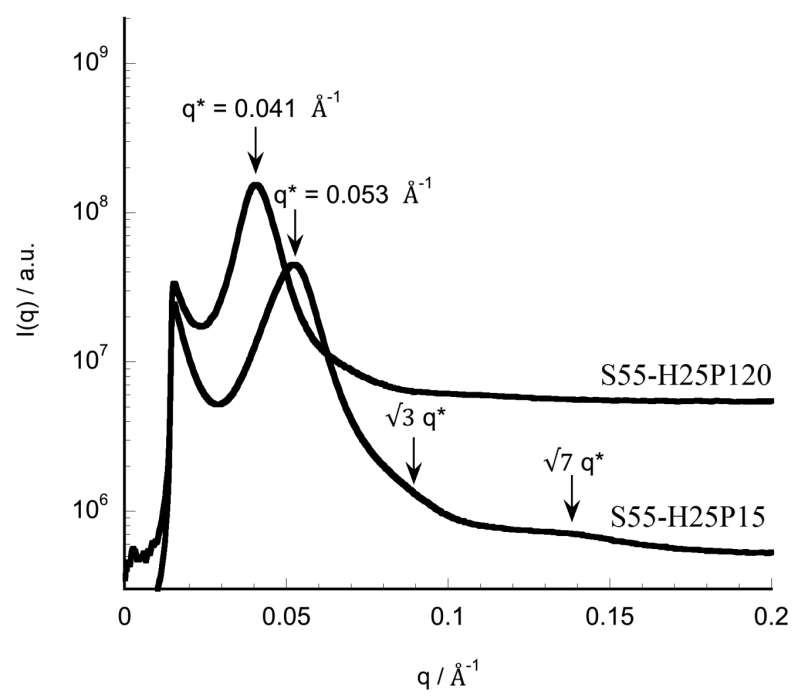

Figure 5. SAXS/WAXS intensity profile of S30-H55P15 and S55-H120P25 samples cast from $10 \% \mathrm{~m} / \mathrm{v}$ acetone solutions and annealed at $120^{\circ} \mathrm{C}$ for $24 \mathrm{~h}$.

\section{Conclusions}

Ordered domains can be fabricated from PS- $b$-PHEMA diblock copolymers synthesized by atom transfer radical polymerization. Self-assembly of chains having volume fraction of PS between 0.25 and 0.27 produces nanostructured materials that consist of hexagonally packed 
PS cylinders in a PHEMA matrix. Upon random conversion of approximately $20 \%$ of the pendant hydroxyl groups of PHEMA into phosphonic diacid groups to produce $\mathrm{P}$ (HEMA-co-PEMA), the hexagonal morphology is still retained but the degree of organization decreases drastically.

\section{Acknowledgments}

Financial support was provided by Conselho Nacional de Desenvolvimento Científico e Tecnológico (CNPq, Grant No. 590070/2010-0) and Fundação de Amparo à Pesquisa do Estado do Rio Grande do Sul (FAPERGS, Grant No. 11/0787-0). The European Synchrotron Radiation Facility (ESRF, France) and the Laboratório Nacional de Luz Síncroton (LNLS, Brazil) are acknowledged for the provision of beam time.

\section{References}

1. van Zoelen, W.; ten Brinke, G.; Soft Mater. 2009, 5, 1568.

2. Houbenov, N.; Haataja, J. S.; Iatrou, H.; Hadjichristidis, N.; Ruokolainen, J.; Faul, C. F. J.; Ikkala, O.; Angew. Chem., Int. Ed. 2011, 50, 2516.

3. Lei, Y.; Yang, S.; Wu, M.; Wilde, G.; Chem. Soc. Rev. 2011, 40, 1247.

4. Fu, G.-D.; Li, G. L.; Neoh, K. G.; Kang, E. T.; Prog. Polym. Sci. 2011, 36, 127.

5. Kim, J. K.; Yang, S. Y.; Lee, Y.; Kim, Y.; Prog. Polym. Sci. 2010, $35,1325$.

6. Tyrrell, Z. L.; Shen, Y.; Radosz, M.; Prog. Polym. Sci. 2010, $35,1128$.

7. Motornov, M.; Roiter, Y.; Tokarev, I.; Minko, S.; Prog. Polym. Sci. 2010, 35, 174.
8. Mann, S.; Nat. Mater. 2009, 8, 781.

9. Okano, T.; Suzuki, K.; Yui, N.; Sakurai, Y.; Nakahama, S.; J. Biomed. Mater. Res. 1993, 27, 1519.

10. Faxalv, L.; Ekblad, T.; Liedberg, B.; Lindahl, T. L.; Acta Biomater. 2010, 6, 2599.

11. Schmidt, V.; Giacomelli, C.; Brisson, A.; Borsali, R.; Mater. Sci. Eng., C 2008, 28, 479.

12. Schmidt, V.; Giacomelli, C.; Lecolley, F.; Lai-Kee-Him, J.; Brisson, A. R.; Borsali, R.; J. Am. Chem. Soc. 2006, 128, 9010.

13. Weinrich, D.; Jonkheijm, P.; Niemeyer, C. M.; Waldmann, H.; Angew. Chem., Int. Ed. 2009, 48, 7744.

14. Lin, P.-C.; Weinrich, D.; Waldmann, H.; Macromol. Chem. Phys. 2010, 211, 136.

15. Pan, J.; Chen, M.; Warner, W.; He, M.; Dalton, L.; Hogen-Esch, T. E.; Macromolecules 2000, 33, 7835.

16. Senshu, K.; Yamashita, S.; Ito, M.; Hirao, A.; Nakahama, S.; Langmuir 1995, 11, 2293.

17. Lee, D. K.; Park, J. T.; Roh, D. K.; Min, B. R.; Kim, J. H.; Macromol. Res. 2009, 17, 325.

18. Davis, K. A.; Charleux, B.; K., M.; J. Polym. Sci., Part A: Polym. Chem. 2000, 38, 2274.

19. Narayanan, T.; Diat, O.; Bösecke, P.; Nucl. Instrum. Methods Phys. Res., Sect. A 2001, 467, 1005.

20. Hammersley, A. P.; Scientific software FIT2D; ESRF, Grenoble, France, 1997, http://www.esrf.eu/computing/scientific/FIT2D/ acessed in July 2009.

21. ESRF, Bm2img - Image processing on BM02 beamline, http://www.esrf.eu/UsersAndScience/Experiments/CRG/ BM02/detectors/process.html accessed in March 2012.

22. Hamley, I.; Castelletto, V. In Soft Matter: Scattering, Imaging and Manipulation, vol. 2; Borsali, R.; Pecora, R., eds.; Springer: New York, 2008, p. 1021.

23. Chu, B.; Hsiao, B. S.; Chem. Rev. 2001, 101, 1727.

Submitted: December 19, 2011

Published online: March 13, 2012 